\title{
Condition Assessment of August A. Busch Bridge Deck Using Portable Seismic Property Analyzer and Ground Penetrating Radar
}

\author{
Samie Hamad1, Wajdi Ammar², Salah Shaniba3 ${ }^{3}$, Abdelmajeed Altlomate4 \\ ${ }^{1}$ Missouri University of Science and Technology, Missouri, USA \\ ${ }^{2}$ University of Colorado Denver, Colorado, USA \\ ${ }^{3}$ Mellitah Oil \& Gas B.V, Tripoli, Libya \\ ${ }^{4}$ Sirte University, Sirte, Libya \\ Email:sraf35@umsystem.edu,wajdi.ammar@ucdenver.edu, salah.shaniba@gmail.com, a.altlomate@su.edu.ly
}

How to cite this paper: Hamad, S., Ammar, W., Shaniba, S. and Altlomate, A. (2022) Condition Assessment of August A. Busch Bridge Deck Using Portable Seismic Property Analyzer and Ground Penetrating Radar. Open Journal of Civil Engineering, 12, 14-21.

https://doi.org/10.4236/ojce.2022.121002

Received: December 9, 2021

Accepted: January 17, 2022

Published: January 20, 2022

Copyright (c) 2022 by author(s) and Scientific Research Publishing Inc. This work is licensed under the Creative Commons Attribution International License (CC BY 4.0).

http://creativecommons.org/licenses/by/4.0/

\begin{abstract}
Ground penetrating radar (GPR) and the portable seismic property analyzer (PSPA) have been extensively used in the past two decades for monitoring, quantifying, and mapping the deterioration of bridge decks. Using PSPA and GPR ensures regular monitoring of bridge conditions, leads to the early detection of deterioration. This research is to address the condition of August A. Busch bridge deck owned by the Missouri Department of Conservation. Visual inspection, GPR, and PSPA data were acquired on the bridge deck. Over $90 \%$ of the bridge deck was in fair to good condition with an average compressive strength of over 2500 psi. GPR data showed no indication of significant deterioration. The overall bridge deck was determined to be in fair to good condition.
\end{abstract}

\section{Keywords}

Ground Penetrating Radar, Portable Seismic Property Analyzer, Bridge Deck, Concrete Deterioration

\section{Introduction}

Of states with the highest percentage rates of deficient bridges in the country, Missouri is in the top five. Out of the 10,400 bridges in Missouri, at least 2000 are structurally deficient, according to the Missouri Department of Transportation [1]. This means that about $20 \%$ of the bridges in Missouri are in serious to poor condition, according to the National Bridge Inventory (NBI) Rating Scale 
[2]. About $50 \%$ of these bridges are 50 years or older.

Bridge decks, like any concrete structure, deteriorate over time. For this reason, regular inspections should be performed to detect potential defects [3]. Most internal defects, like the early stages of reinforcement corrosion in the bridge deck, cannot be detected by performing visual inspections or using traditional inspection methods like chain dragging or hammer soundings [4]. These defects can affect the serviceability of the bridge.

Non-destructive testing tools, such as GPR and PSPA, extensively used in the past two decades for monitoring, quantifying, and mapping the deterioration of bridge decks [5]. Using PSPA and GPR ensures regular monitoring of bridge conditions, leads to the early detection of deterioration, and plays a major role in bridge serviceability. This is important, as not knowing the integrity of bridge decks increases maintenance costs and presents public safety hazards.

PSPA and GPR data were acquired on August A. Busch bridge deck owned by the Missouri Department of Conservation. The intent of data collection was to determine the condition of the decks (that is, to identify areas where the bridge deck is degraded), and to determine and demonstrate the functionality of using GPR and PSPA together.

\section{Concrete Bridge Decks}

A bridge deck is the surface of the bridge that provides a structural element for overpass traffic. It is a structural element of the superstructure, and it can be built of concrete, steel, open grating, or wood. The primary function of a bridge deck is carrying loads from overpass traffic (compression or tension) over to the columns to the foundation.

\subsection{Bridge Deck Overview}

The bridge is located at August A. Busch Conservation Area, about 30 miles west of St. Louis, Missouri (Figure 1). The bridge was built in 2008 and is owned by the Missouri Department of Conservation. The deck is comprised of a reinforced concrete slab about 9 inches thick, and measures 14 feet wide by 36 feet long.

\subsection{Bridge Deck Visual Evidence}

Visual inspection was performed on both the top and bottom of the bridge deck. Small grooves (less than $1 / 2$ inch deep) were located the middle of the bridge and on the side of the bridge deck. The visual data was used to create a map of the defects for comparison with the PSPA data and the GPR data (Figure 2). The bottom of the bridge deck shows no sign of deterioration.

\subsection{PSPA}

Field scans were acquired based on point loading. Dense grid was used to provide high resolution data. A total of 40 stations were tested, and at least three repeated samples were taken at each station. The distance between each station 


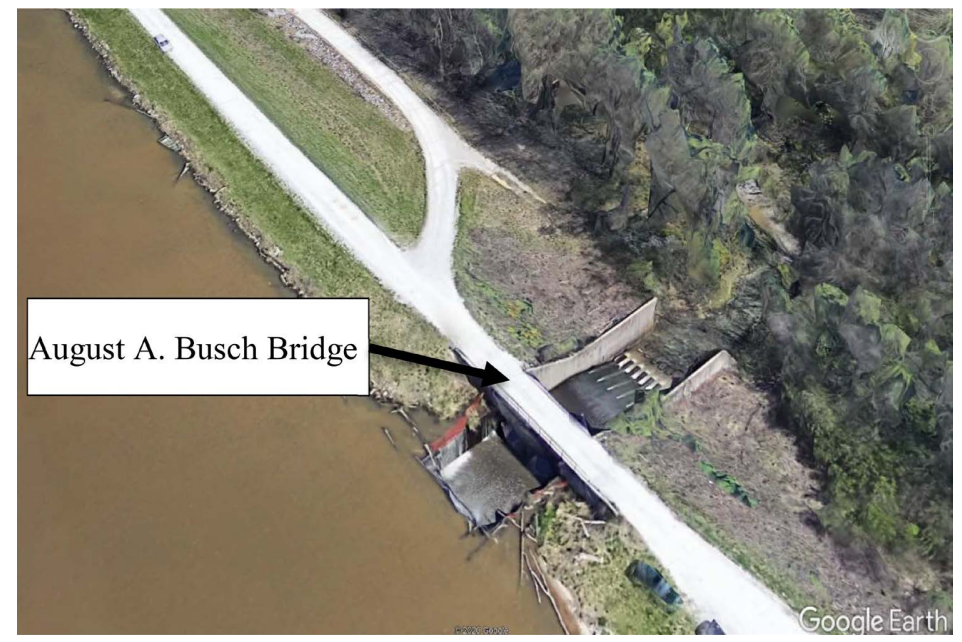

Figure 1. Map shows the location of the bridge on the map.

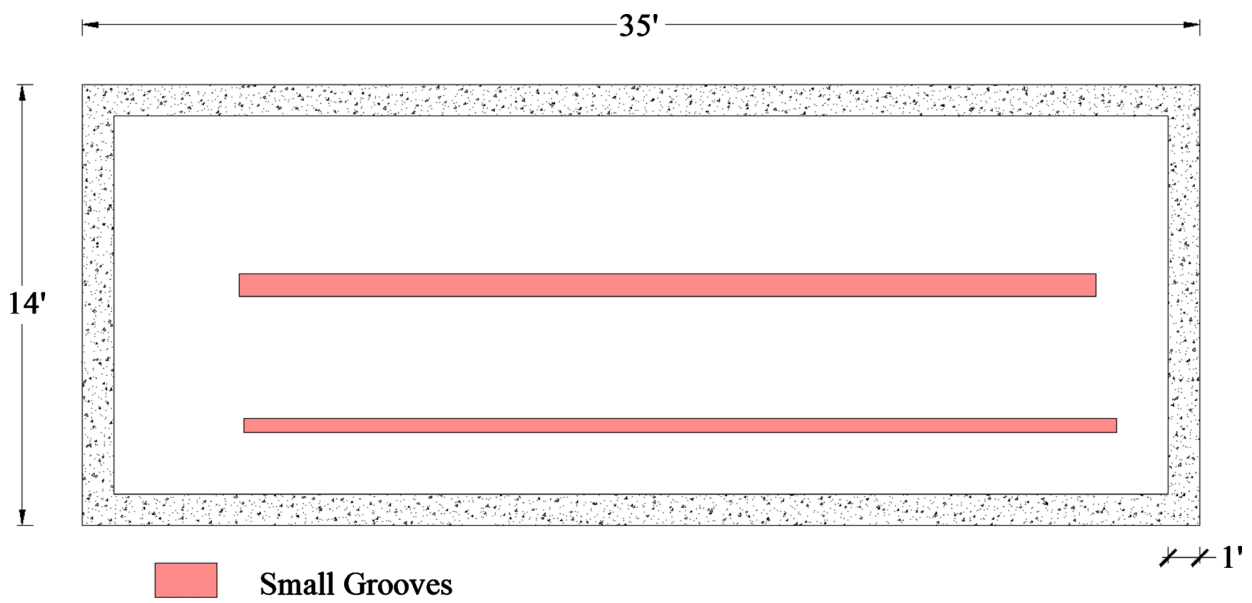

Figure 2. Detail map shows the type of the deterioration and its location on the bridge deck (visual inspection map was generated to show the types and locations of the defects at the time of the inspection).

was 4 feet in the longitudinal direction and 2 feet in the transverse direction, as shown in Figure 3.

The American Concrete Institute (ACI) specified the minimum average compressive strength of $2500 \mathrm{psi}$ for a concrete structure. A concrete deck with average compressive strength of 2500 psi or less is considered poor condition. Table 1 shows the minimum requirement of the average compressive strength by the type of concrete structure [6].

3D map was generated showing the elastic modulus of the bridge deck (Figure 4). Another 3D map was generated showing the average compressive strength of the bridge deck (Figure 5).

\subsection{GPR}

The GPR data were used to measure the variations in the amplitude reflected of each reinforcement steel bar; to measure the variations in the embedment depth 


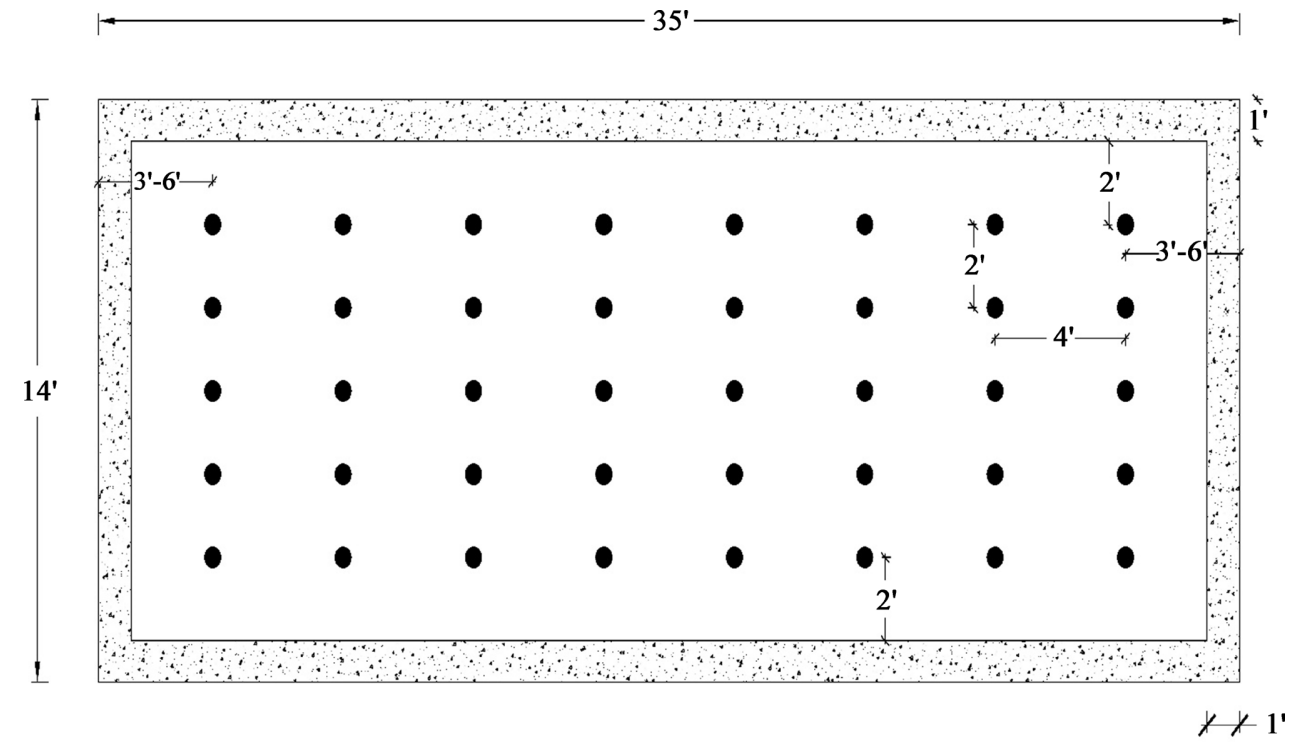

Figure 3. PSPA points location on August A. Busch bridge deck layout of the location of the PSPA tests (5 lines total with 8 stations per line), total of 40 station.

Table 1. Specified average compressive strength by type of construction.

\begin{tabular}{cc}
\hline Type or location of concrete construction & Specified average compressive strength, psi \\
\hline Concrete fill & Below 2000 \\
Basement and foundation walls and slabs, walks, patios, steps and stairs & $2500-3500$ \\
Driveways, garage and industrial floor slabs & $3000-4000$ \\
Reinforced concrete beams, slabs, columns and walls & $3000-7000$ \\
Precast and pre-stressed concrete & $4000-7000$ \\
High-rise buildings (columns) & $10,000-15,000$ \\
\hline
\end{tabular}

Note: for information purposes only; the plans and specifications give actual strength requirements for any job under consideration.

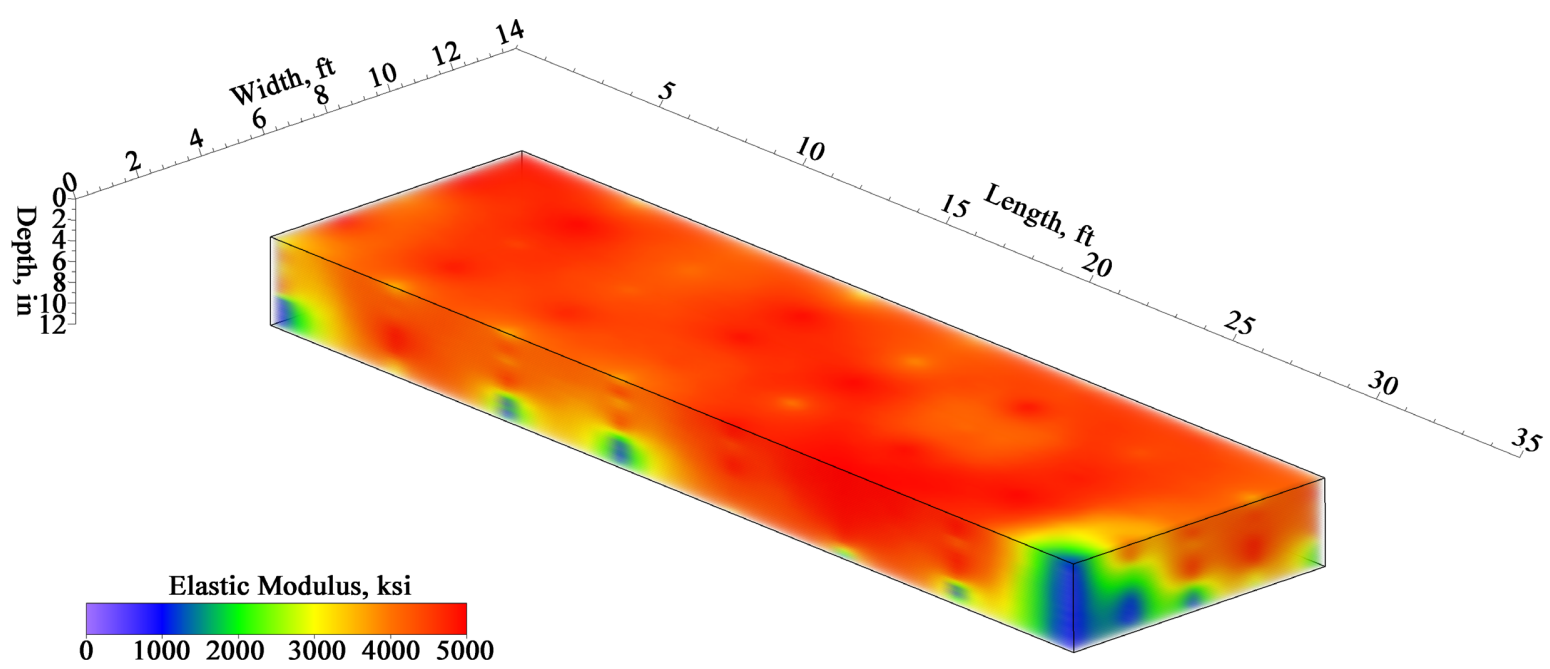

Figure 4. 3D map of the average elastic modulus of August A. Busch bridge deck. 
of each reinforcement steel bar; and to generate a map showing amplitude variation across the bridge deck.

Starting from the north east corner of the bridge and one foot from the edge, 11 data files were collected in 11 lines, in the same direction as the traffic flow, with $1 \mathrm{ft}$. spacing between each line (Figure 6).

Table 2 shows the rating scale of the concrete deck based on the magnitude value of the amplitude.

Figure 7 is a side-by-side comparison between the 2D map of the average compressive strength and the 2D map of GPR amplitude reflection. The figure shows consistency where the area of the bridge deck was expected to be deteriorated. It is also very consistent where the concrete was expected to be in a good shape.

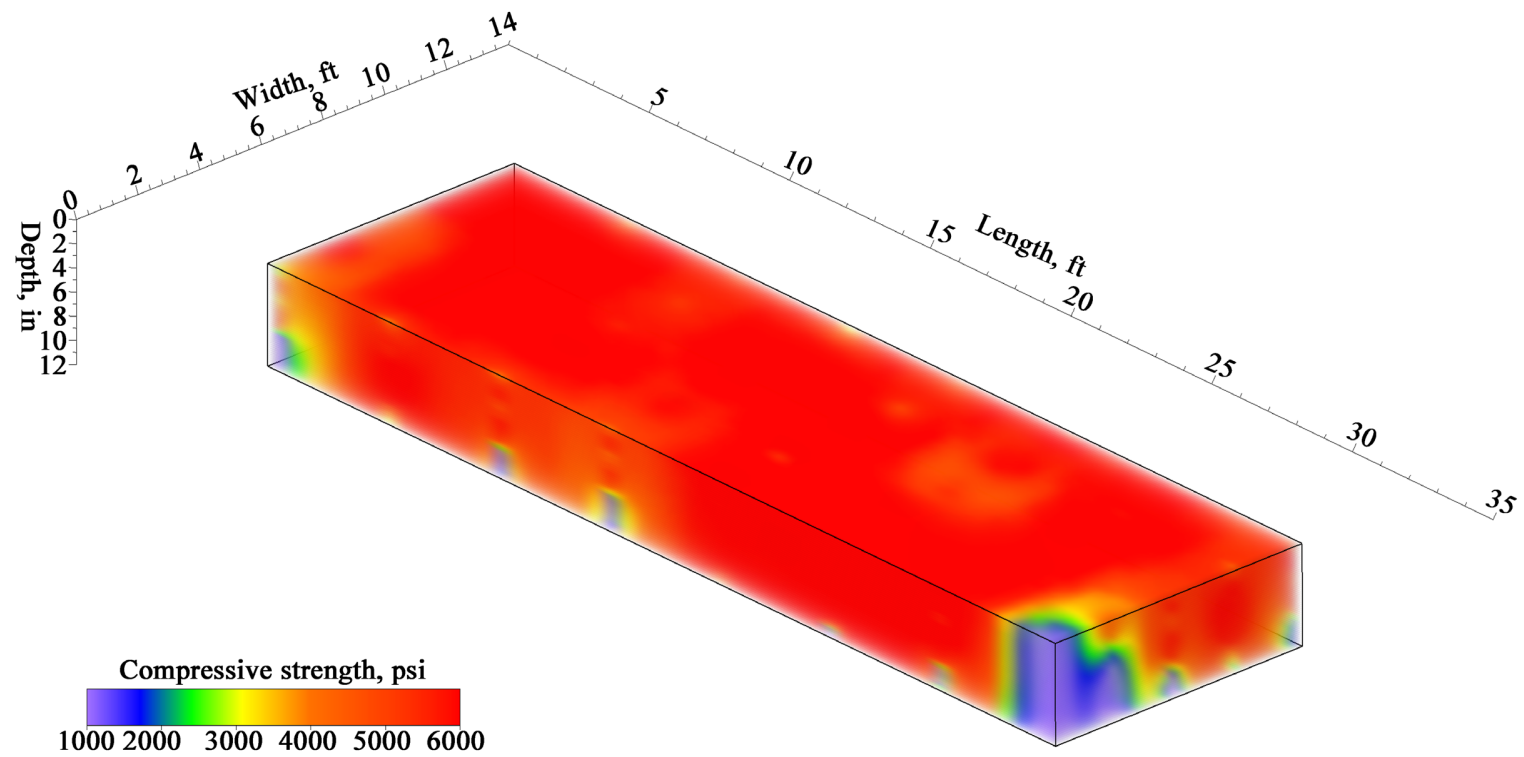

Figure 5. 3D map of the average compressive strength of August A. Busch bridge deck.

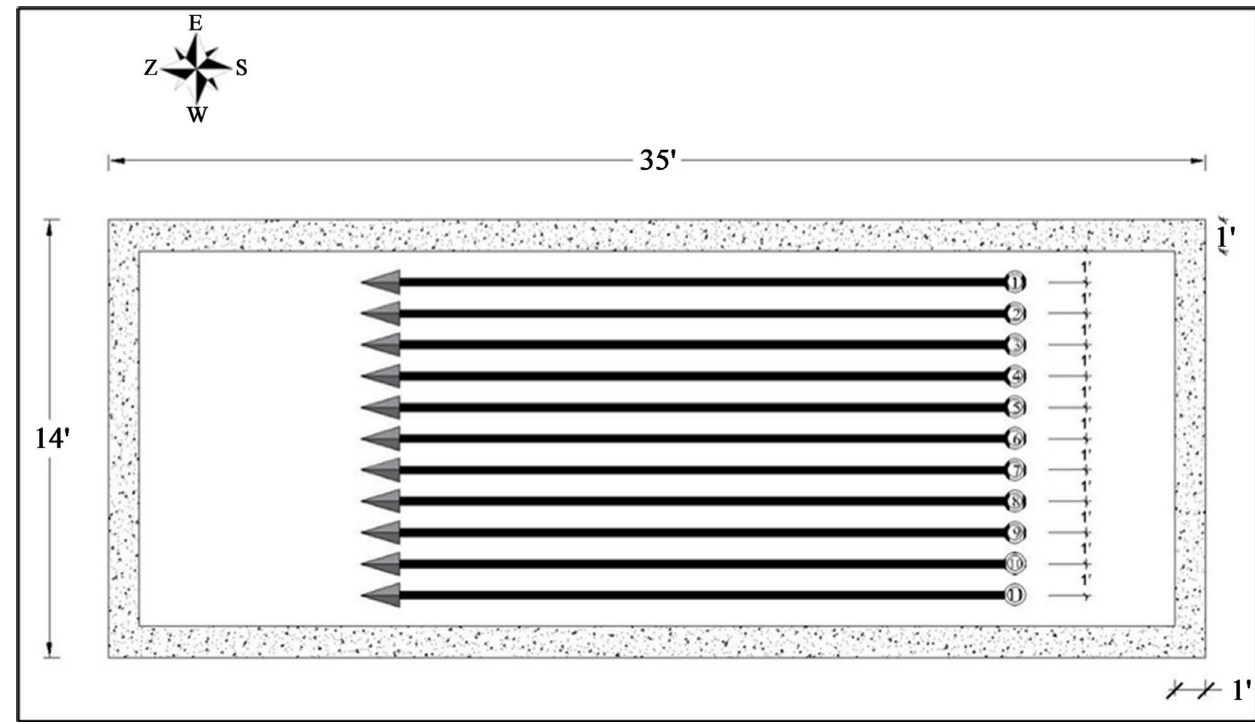

Figure 6. GPR layout. 
Table 2. GPR amplitude range rating condition scale.

\begin{tabular}{cc}
\hline Concrete condition & Amplitude range (dB) \\
\hline Good & $29-32$ \\
Fair & $25-29$ \\
Bad & $23-25$ \\
Serious & $19-23$ \\
\hline
\end{tabular}

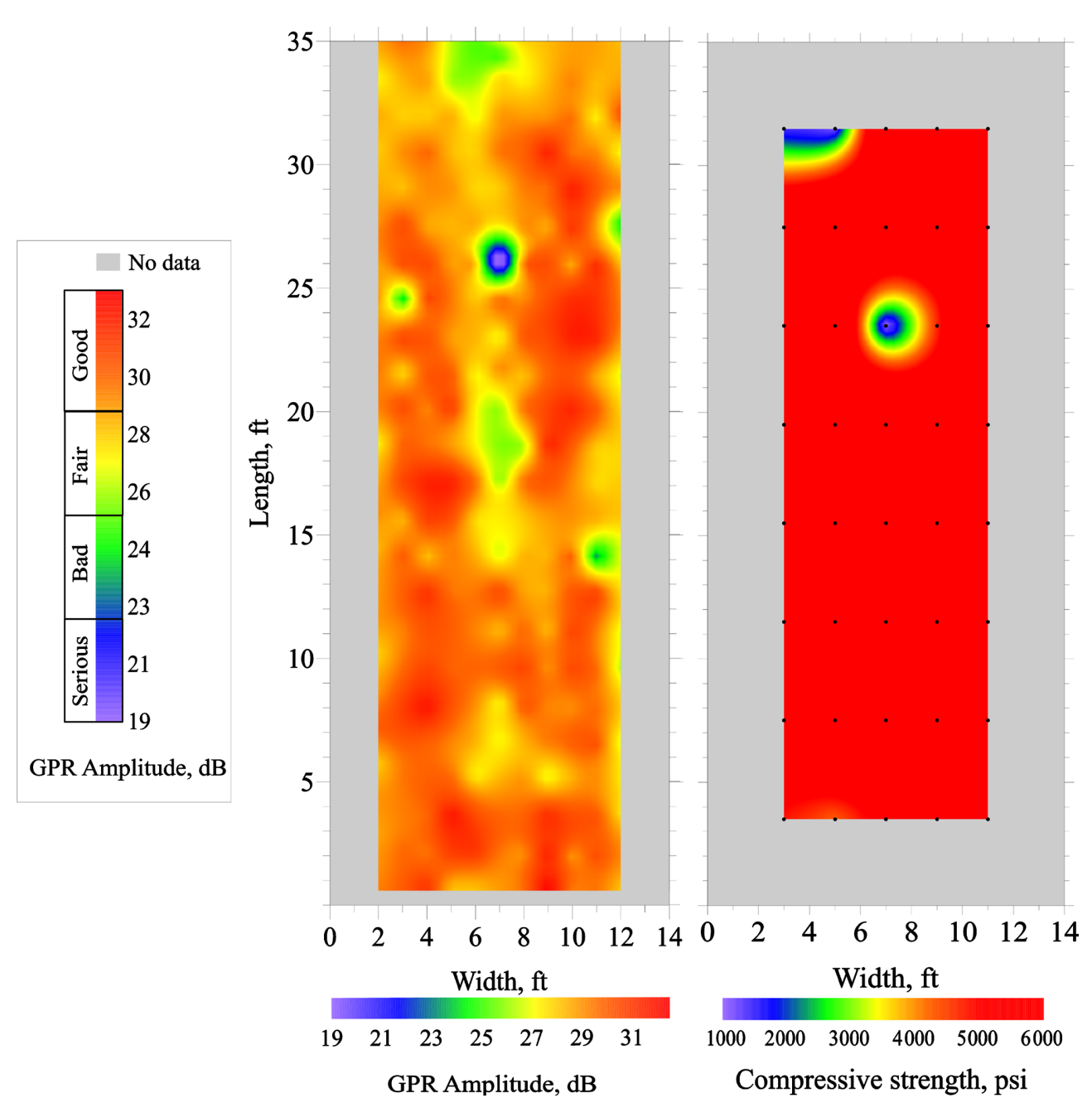

Figure 7. Compressive strength vs. GPR amplitude of the bridge deck.

Based on PSPA data, a 3D map was generated for the area of the good-quality concrete (average compressive strength of 2000 psi or more), as shown in Figure 8.

\section{Conclusions and Recommendations}

Bridge deck condition assessment was conducted at August A. Busch bridge deck using PSPA and GPR tools, along with visual inspection. The PSPA tool measured the elastic modulus of the concrete bridge deck. Measuring the elastic 


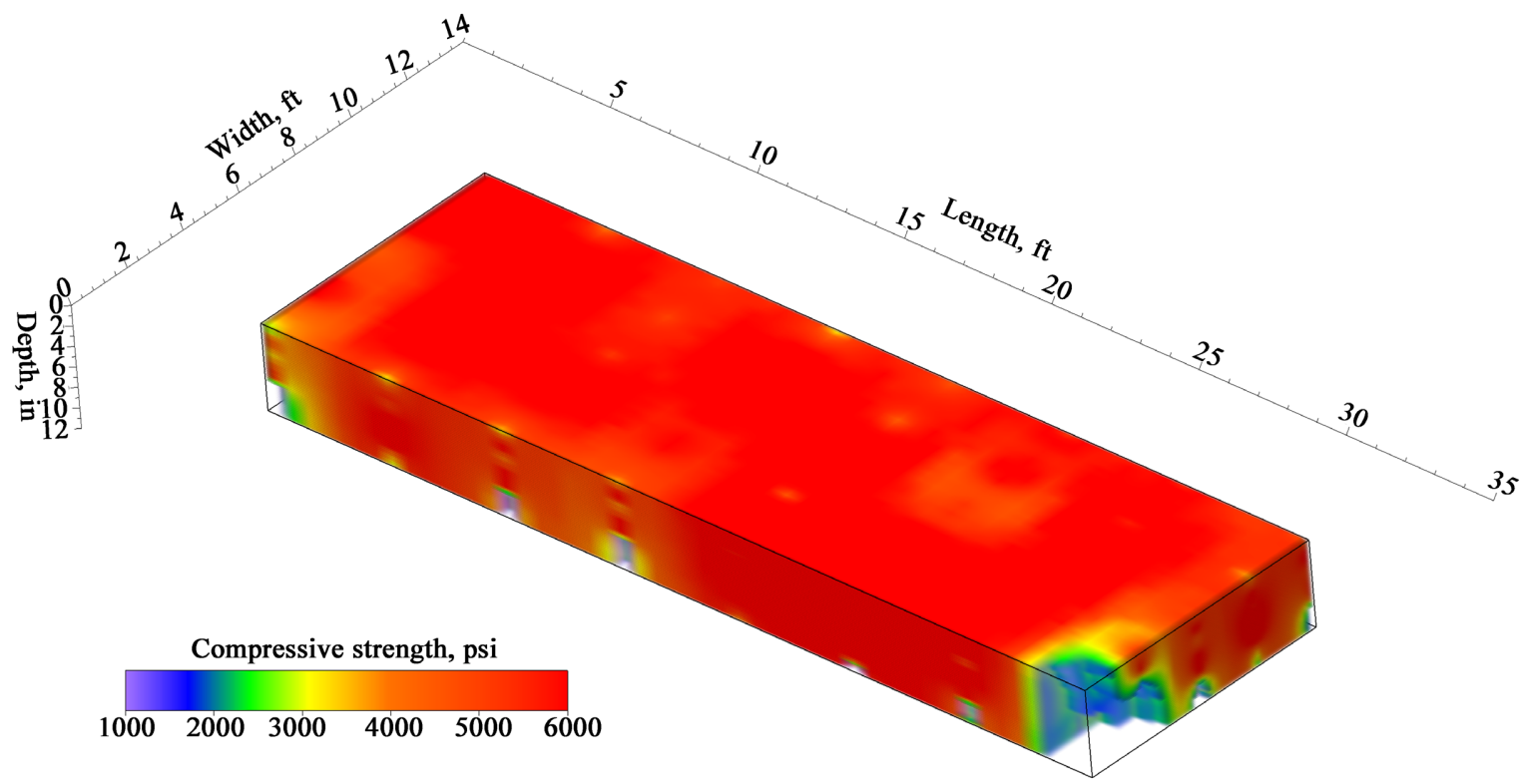

Figure 8. 3D map of area of good-quality concrete.

modulus of the concrete bridge deck using PSPA tool and relating it to the compressive strength gave a solid condition assessment of the bridge deck (as compressive strength is one of the main factors used in assessing the condition of a concrete deck).

The GPR tool responded mostly to the presence moisture content of the concrete bridge deck. GPR data were interpreted with the expectation that moisture content is a function of porosity, and that porosity is a function of the integrity. GPR tool was also used to accurately measure the pattern, placement, and density of reinforcing steel.

The interpretations of the data acquired using both tools correlated very well with each other and with visual inspection.

\section{Conflicts of Interest}

The authors declare no conflicts of interest regarding the publication of this paper.

\section{References}

[1] Hamad, S., Ammar, W. and Shaniba, S. (2021) Condition Assessment Using None Destructive Tests at Montauk Bridge Deck. International Journal for Research in Applied Science \& Engineering Technology, 9, 581-588. https://doi.org/10.22214/ijraset.2021.39337

[2] (2021) ASCE's 2021 Infrastructure Report Card. https://infrastructurereportcard.org/cat-item/bridges/

[3] Samie, H., Abdurraouf, O., Neil, A. and Wajdi, A. (2021) Use of Portable Seismic Property Analyzer and Ground Penetrating Radar to Assess Bridge Decks. Symposium on the Application of Geophysics to Engineering and Environmental Problems Proceedings, 327. https://doi.org/10.4133/sageep.33-179 
[4] Parrillo, R. and Roberts, R. (2006) Bridge Deck Condition Assessment Using Ground Penetrating Radar. ECNDT, 4, 1-12.

[5] Gucunski, N., et al. (2017) RABIT: Implementation, Performance Validation and Integration with other Robotic Platforms for Improved Management of Bridge Decks. International Journal of Intelligent Robotics and Applications, 1, 271-286. https://doi.org/10.1007/s41315-017-0027-5

[6] ACI Committee 222 (2001) ACI 222R-01 Protection of Metals in Concrete against Corrosion Reported by ACI Committee 222. Aci Committee Report, 1, 1-41. 